\title{
The D2 Antagonist Spiperone Mimics the Effects of Olfactory Deprivation on Mitral/Tufted Cell Odor Response Patterns
}

\author{
Donald A. Wilson and Regina M. Sullivan \\ Department of Zoology, University of Oklahoma, Norman, Oklahoma 73019
}

\begin{abstract}
Wistar rats had a single nare occluded on postnatal day 30 , depriving the ipsilateral olfactory bulb of odor stimulation. The deprivation lasted for either 1-2 months (short-term) or 12 months (long-term). As prevlously reported, deprivation greatly reduced tyrosine hydroxylase immunoreactivity (the rate limiting enzyme for dopamine synthesis) in the glomerular layer of the ipsilateral olfactory bulb. The nare was then reopened and odor response patterns of $\mathrm{mi}-$ tral/tufted cells were examined. The proportion of mitral/ tufted cell single-units responding to a single odor was enhanced by deprivation. Furthermore, the proportion of mitral/tufted cells responding to more than one odor was increased by deprivation, suggesting a decrease in discrimination. Finally, in undeprived bulbs, the dopamine $D_{2}$ receptor antagonist spiperone mimicked the effects of deprivation on mitral/tufted cell odor response patterns. The results are interpreted as an activity-dependent dopamine modulation of lateral and feedback inhibition in the olfactory bulb, and are compared with similar events in the dark-adapted retina.
\end{abstract}

[Key words: olfaction, olfactory deprivation, sensory deprivation, dopamine, mitral/tufted cells, molecular receptive field]

Sensory system function is modulated by the environment in which that system operates. This plasticity can be expressed in both developing and mature organisms. One form of sensory experience that has been examined in a number of sensory modalities is deprivation. The specific consequences of sensory deprivation are dependent on the sensory system and species involved, the age at onset and duration of the deprivation, and the region within the sensory pathway examined.

The visual system is an excellent example, where the primary visual pathway, retina-thalamus-visual cortex, shows differential responses to deprivation. That is, while early deprivation produces marked changes in visual cortical response patterns to stimuli presented to the deprived eye, response patterns in the thalamus are only minimally changed (Movshon and Kiorpes, 1990). On the other hand, while there are no long term anatomical or physiological effects of deprivation on the retina, it is temporarily modified by deprivation, even in mature animals. Depriving a retina of light for minutes to hours (dark adaptation)

\footnotetext{
Received Jan. 9, 1995; revised Mar. 10, 1995; accepted Mar. 17, 1995.

This work was supported by Grant DC00866 from NIH to D.A.W. and R.M.S. We thank Dr. Joseph Bastian for helpful discussion throughout this work and Dr. P. Duchamp-Viret for comments on the manuscript.

Correspondence should be addressed to Donald A. Wilson at the above address.

Copyright (C) 1995 Society for Neuroscience $0270-6474 / 95 / 155574-08 \$ 05.00 / 0$
}

enhances retinal ganglion cell responsiveness to subsequent light stimulation (Barlow et al., 1957; Mangel and Dowling, 1985). In mammals, this enhancement is produced by a dark-induced reduction in lateral inhibition (Daw et al., 1989), that is associated with (Luvone et al., 1978), and can be mimicked by (Thier and Alder, 1984; Jensen and Daw, 1986), a decrease in dopamine activity.

The primary olfactory system of the rat, olfactory epitheliumolfactory bulb-olfactory cortex, is similarly differentially affected by deprivation during early development. Olfactory deprivation is produced by nasal occlusion that reduces airflow over the ipsilateral olfactory epithelium. In the olfactory epithelium of the rat, early deprivation lasting 2-4 weeks produces a slight reduction in receptor cell number and cell proliferation (Farbman et al., 1988; Cummings and Brunjes, 1994). In the rat olfactory bulb, however, similar deprivation produces dramatic reductions in bulb volume and cell number (Meisami, 1976; Meisami and Safari, 1981; Frazier and Brunjes, 1988). The most severely affected neurons are the late developing inhibitory interneurons-granule cells and juxtaglomerular cells. Late-onset deprivation has little effect on olfactory bulb anatomy in the rat (Brunjes and Borror, 1983), although there are species differences (e.g., Maruniak et al., 1989). Very little is known about deprivation effects on the olfactory cortex and other higher olfactory centers (Brunjes, 1994).

As in the retina, olfactory bulb dopamine is regulated by sensory input. Olfactory receptor axons enter the olfactory bulb and arborize within spherical regions of neuropil called glomeruli. Within glomeruli, receptor axons synapse onto the dendrites of mitral and tufted cells which are the primary output neurons of the bulb, and juxtaglomerular interneurons. Glomeruli operate as functional units (Benson et al., 1985), and are believed to respond to a limited selection of odors (Jourdan et al., 1980). Juxtaglomerular cells are hypothesized to mediate lateral inhibition between glomeruli (Mori, 1987). A subset of the juxtaglomerular neurons express both dopamine and GABA neurotransmitters (Gall et al., 1987). Olfactory deprivation reduces olfactory bulb dopamine content by as much as 75\% (Brunjes et al., 1985; Wilson and Wood, 1992) and reduces tyrosine hydroxylase expression in juxtaglomerular neurons (Baker, 1990; Wilson and Wood, 1992), without modifying GABA expression (Baker, 1990). In contrast to the anatomical effects of olfactory deprivation described above, deprivation effects on dopamine synthesis in the rat are not age dependent (Baker, 1990; Wilson and Wood, 1992).

Thus, as in the mammalian retina, dopamine may modulate bulb responses to changes in sensory input. It has recently been demonstrated that dopamine inhibits olfactory nerve input, prob- 
ably via presynaptic $D_{2}$ receptors (Nickell et al., 1990; Berkowicz et al., 1994). Therefore, removal of dopamine (as in deprivation) should enhance the effectiveness of olfactory nerve excitation of bulb neurons. In fact, we have previously demonstrated that early onset deprivation, which reduces dopamine and modifies olfactory bulb anatomy, enhances bulb mitral/tufted cell responses to both odors (Guthrie et al., 1990) and electrical stimulation of the olfactory nerve (Wilson and Wood, 1992).

The present report explores the effects of late-onset olfactory deprivation on olfactory bulb mitral/tufted cell response patterns to odors, and examines the ability of the dopamine $\mathrm{D}_{2}$ receptor antagonist spiperone to mimic those responses. The results suggest that both deprivation and spiperone enhance mitral/tufted cell responsiveness and decrease odor discrimination.

\section{Materials and Methods}

Subjects. Male Wistar rats (Hilltop Lab $\Lambda$ nimals, Scottdale, $\mathrm{P} \Lambda$, and Charles River Labs, Wilmington, MA) were used as subjects $(n=19)$. Animals used in the deprivation experiments were born in our colony and weaned at postnatal (PN) day 23-25. Animals were housed in polypropylene cages lined with wood chips. All animals were supplied ad lib food and water and maintained on a 12:12 light cycle, with lights on at 0700 .

Deprivation. On PN30, rats were anesthetized with pentobarbital ( 50 $\mathrm{mg} / \mathrm{kg}$ ) and had a single nare cauterized (Meisami, 1976). The cautery resulted in a scab and subsequent scarring that completely occluded the nare. Control rats were cauterized on the top of the snout. Following recovery from the ancsthesia, animals were returned to their home cage for 2 months (short-term; $n=7$ ) or for 12-14 months (long-term; $n=$ 6). In some deprived animals, recordings were made from both deprived and undeprived bulbs rather than just from a single bulb. The additional testing from these animals did not appear to influence results obtained (e.g., percent of cells responding to odors) when compared to animals where only one bulb was tested.

Electrophysiological recordings. Animals were anesthetized with urethane $(1.5 \mathrm{gm} / \mathrm{kg})$ and the sealed nare was surgically reopened PE160 (1.14 mm i.d.) tubing was inserted into the reopened nare to maintain patency. The previously opened nare was sealed with low melting point paraffin. In control animals, one nare was sealed with paraffin and the other had PE160 tubing inserted to allow comparable airflow between groups. The olfactory bulb was surgically exposed and covered in warmed mineral oil. A bipolar, stainless steel stimulating electrode was implanted in the lateral olfactory tract (LOT). Mitral/ tufted cell single-unit activity was recorded with glass micropipettes filled with $2 \mathrm{M} \mathrm{NaCl}$. Single-unit recordings were verified with interval histograms showing a refractory period following single spikes. Mitral/ tufted cells were identified by the ability to antidromically activate them with stimulation of the LOT. Single-unit activity was amplified, bandpass filtered and passed through a window amplitude discriminator that sent trigger pulses to a CED 1401plus interface for spike train analysis with SPIKE 2 software for the Macintosh (Cambridge Electronic Design).

In addition, in the long-term deprivation animals, evoked field potentials to paired-pulse LOT stimulation were examined $(1000 \mu \mathrm{A}, 10-80$ msec inter-pulse intervals). Responses to the LOT stimuli were recorded in the granule cell layer and peak to peak amplitudes of the large positive wave were measured (see Fig. 2). Suppression of response amplitude to the second pulse is due to granule cell mediated inhibition of mitral/tufted cells (Mori, 1987), which has been shown to be sensitive to early onset deprivation (Wilson et al., 1990; Wilson and Wood, 1992).

Odor stimulation. A continuous stream of humidified air $(500 \mathrm{ml} /$ min) was presented $1 \mathrm{~cm}$ from the nares of the freely breathing animal. Saturated odor vapor was added to the air stream with a computer controlled syringe pump that forced air through filter paper soaked with either citral (Sigma) or peppermint extract (McCormick). Syringe pump speed was varied to deliver different final concentrations of citral $\left(10^{-1}\right.$, $10^{-2}$, and $10^{-3}$ dilution of saturated vapor). Peppermint was tested at a single concentration $\left(10^{-1}\right)$. Odor stimulus duration was $4 \mathrm{sec}$, and firing rate during the stimulus was compared to firing rate during the $4 \mathrm{sec}$ preceding odor onset with an ANOVA. The cell was considered to have responded to the odor if there was a statistically significant change in firing rate during the odor stimulus. Single-unit odor discrimination was defined here as a cell that responded to one odor but not the other.
(However, it should be noted that no matter how similar a neuron's responses to two different odors may appear, it is still possible that undetected differences may exist allowing for odor discrimination by that cell; such as difference in response latency, intensity, or some as yet undescribed critical parameter.)

Only one stimulus intensity $\left(10^{-1}\right)$ was used for both odors in the long-term deprivation study.

Pharmacology. Five undeprived animals (275-480 gm) were used to examine the effects of the $D_{2}$ antagonist spiperone on mitral/tufted cell responses to odors. Recordings were made as described above. After response patterns were characterized for 5-10 cells, the animal was injected with spiperone hydrochloride $(0.2 \mathrm{mg} / \mathrm{kg}$, s.c. injection; obtained from R.B.I.). Response patterns of additional cells were then determined, 30-90 min after the injection. Throughout the recording session, respiration was monitored with a piezoelectric device that recorded movements of the chest wall. This device allowed accurate measurement of respiration rate without interfering with airflow near the nares or respiratory tract.

In addition to monitoring respiration rate, the respiratory movements were used for analysis of single-unit activity phase relationships to the respiratory cycle. A phase histogram $\left(6^{\circ}\right.$ bin width) was acquired throughout the entire sampling period, triggered by the onset of the respiratory wave (see Fig. 6). Data from individual phase histograms were then divided into six periods $\left(0-60^{\circ}, 60-120^{\circ}, 120-180^{\circ}\right.$, etc.). Significant single-unit activity-respiration cycle phase relationships were determined by analyzing spikes counts across periods with an ANOVA for each cell.

Immunohistochemistry. To demonstrate that the well documented (Baker, 1990; Wilson and Wood, 1992) deprivation-induced decrease in tyrosine hydroxylase immunoreactivity in the olfactory bulb also occurred with the age at onset and duration of deprivation used here, a single animal was deprived at PN30 as described above. On PN60, the animal was overdosed with pentobarbital and perfused transcardially with $4 \%$ paraformaldehyde in $0.1 \mathrm{M}$ phosphate buffer. The olfactory bulbs were sectioned horizontally $(40 \mu \mathrm{m})$ and processed for tyrosine hydroxylase immunoreactivity (tyrosine hydroxylase primary antibody from Eugene Tech) using standard avidin-biotin-peroxidase (Vector Labs) immunohistochemical procedures (Wilson and Wood, 1992).

\section{Results}

Late-onset olfactory deprivation produced a marked decrease in tyrosine hydroxylase immunoreactivity in the glomerular layer of the olfactory bulb compared to the contralateral, undeprived bulb (Fig. 1), as previously reported (Baker, 1990; Wilson and Wood, 1992).

\section{Late onset, long-term deprivation}

Granule cell mediated inhibition of mitral/tufted cells, as measured with paired-pulse LOT stimulation, was not significantly influenced by late onset deprivation lasting 12 or more months (ANOVA, main effect of condition and condition $X$ inter-pulse interval interaction, $F$ values $<1$, NS). As shown in Figure 2, short inter-pulse intervals produced inhibition of the test response amplitude (i.e., second response was smaller than first). This effect was indistinguishable between groups.

Mitral/tufted cell single-unit responses to odors were modified by long-term deprivation (Fig. 3). A total of 35 cells were recorded in three control bulbs, and 34 cells recorded in four deprived bulbs. All stimuli were at $10^{-1}$ dilution of saturated vapor. Mean response rates (percent of cells responding) were calculated for each bulb and averaged within groups. The percentage of cells responding to at least one odor was increased in deprived bulbs compared to control bulbs, although not quite reaching statistical significance $[t(5)=2.30, p=0.07]$. Furthermore, the percentage of cells responding to both citral and peppermint increased more than threefold in the deprived bulbs [percentage of cells responding to both odors, control $=7.7 \pm 4 \%$, deprived $26.5 \pm 5 \% ; t(5)=2.77, p<0.05)$. 

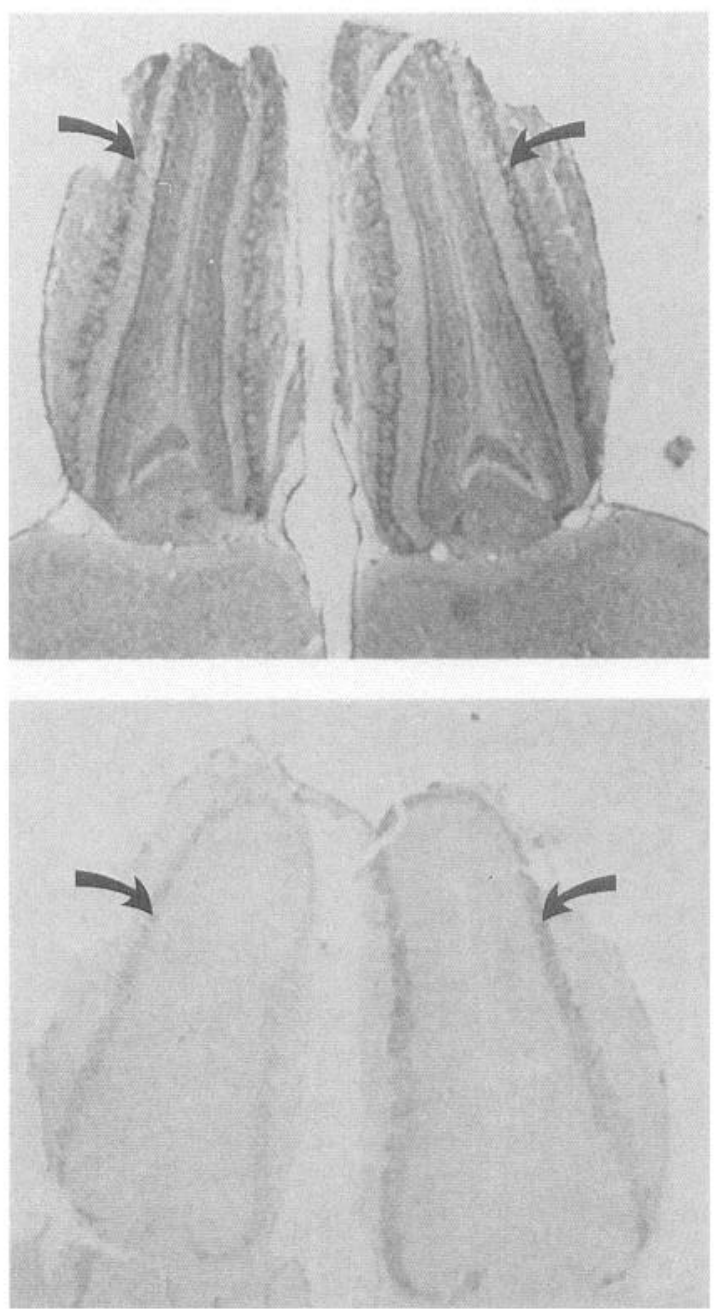

Figure 1. Representative photomicrograph of tyrosine hydroxylase immunostaining in the glomerular layer from a deprived olfactory bulb (left) the contralateral, undeprived olfactory bulb (right). The top section was counterstained with cresyl violet to show cell layers. Olfactory deprivation markedly reduces TH-immunoreactivity of juxtaglomerular neurons. Arrows point to the glomerular layer. The two sections are from the same animal though not directly neighboring each other.

\section{Late onset, short-term deprivation}

A total of 51 cells were recorded in five control bulbs and 51 cells recorded in five bulbs deprived for $60 \mathrm{~d}$. There was no significant difference in spontaneous activity rates between cells recorded in control and deprived bulbs [control, mean $=12.4$ $\pm 1.3 \mathrm{~Hz}$; deprived, mean $=10.6 \pm 1.2 \mathrm{~Hz} ; t(101)=1.06$, NS]. Figure 4 shows examples of responses to odors at different intensities and reproducibility of those responses from a representative cell in a deprived animal. As with long-term deprivation, short-term deprivation produced a marked decrease in the ability of mitral/tufted cells to discriminate between the odors tested. Of cells tested with both odors in the control bulbs, 1.6 $\pm 1.6 \%$ responded to both odors while $25.6 \pm 7 \%$ of cells in deprived bulbs responded to both odors $[t(8)=3.48, p<0.01]$.

In response to citral, cells in deprived bulbs showed a large increase in responsiveness at individual intensities (Fig. 5). The percentage of mitral/tufted cells in both control and deprived bulb responding to citral increased with increasing odor intensity [group $\times$ intensity ANOVA, main effect of intensity, $F(2,16)=$

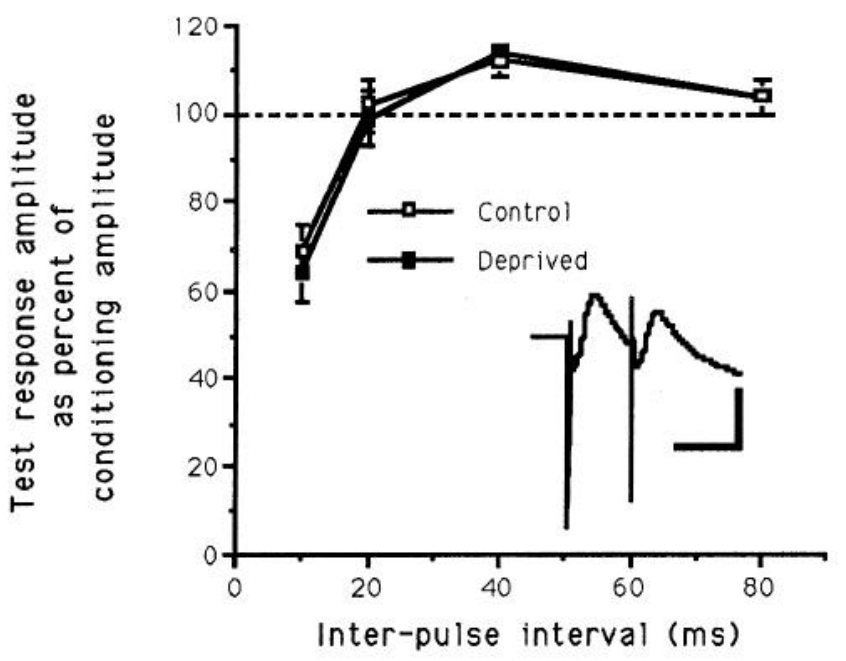

Figure 2. LOT paired-pulse inhibition in control and late-onset, longterm deprived olfactory bulbs. Inset shows representative evoked potentials at $10 \mathrm{msec}$ inter-pulse interval. Late onset deprivation did not affect paired-pulse inhibition. Calibration markers are $10 \mathrm{msec}$ and 2 $\mathrm{mV}$.

$10.82, p<0.01]$. While almost no cells in either group responded to citral at the lowest intensity tested $\left(10^{-3}\right)$, significantly more cells in the deprived bulbs responded at higher intensities [ANOVA main effect of group, $F(1,16)=6.36, p<0.05$ ]. Post hoc Fisher tests revealed a significant difference between groups in response rates to the $10^{-1}$ intensity $(p<0.05)$, with the $10^{-2}$ intensity not quite reaching significance.

\section{Spiperone}

As a first step in exploring the relationship between deprivationinduced loss of glomerular layer dopamine and the observed changes in mitral/tufted cell response patterns to odors, the ef-

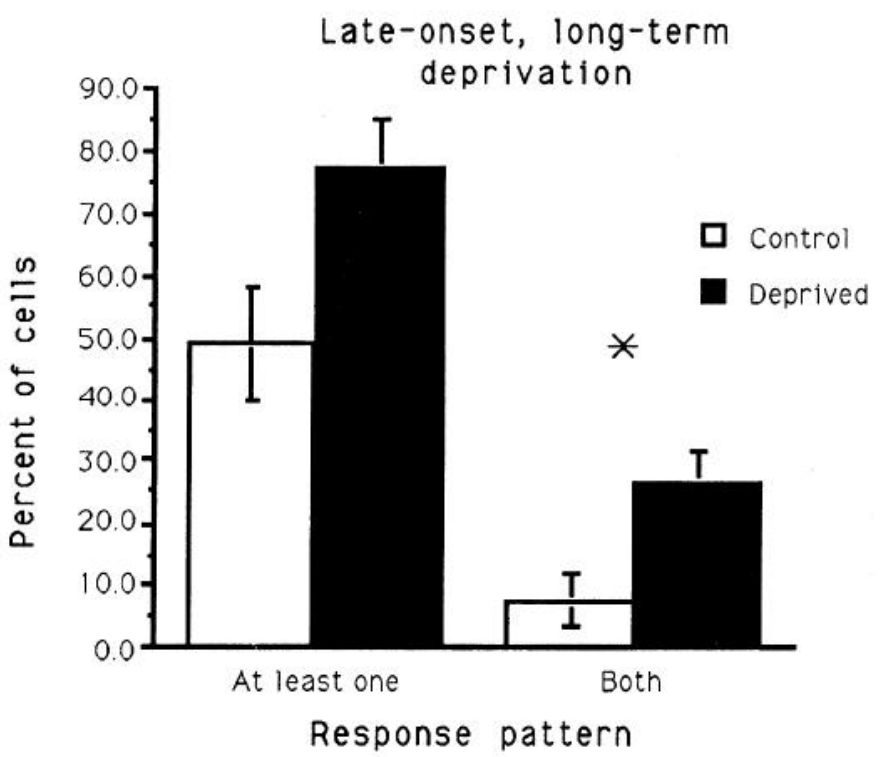

Figure 3. Effects of late-onset, long-term deprivation on mitral/tufted cell single-unit responses to odors. Long-term deprivation increased odor responsiveness and significantly reduced odor discrimination as shown by the increase in the proportion of individual cells responding to both test odors. Asterisk represents significant difference from control, $p<0.05$. 


\section{L1940-3/3 DEPRIVED PN30-PN90}
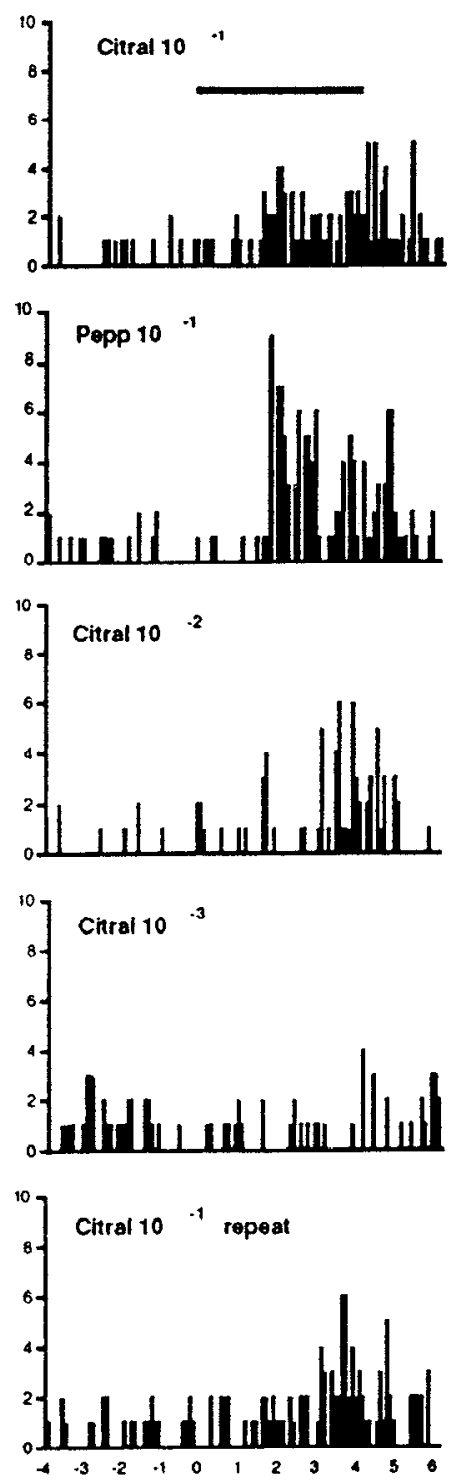

Figure 4. Representative examples of single-unit responses to odors at different concentrations in a late-onset, short-term deprived animal. Each peristimulus time histogram is a cumulative response to three stimuli. Order of graphs from top to bottom is the order of stimulus presentation. Odor presented at time 0 for $4 \mathrm{sec}$ as marked by horizontal bar.

fects of spiperone hydrochloride $(0.2 \mathrm{mg} / \mathrm{kg}$, s.c. $)$ on odor response patterns were examined in five animals. Mitral/tufted cell responses to odors were examined both before $(n=34$ cells $)$ and after ( $n=35$ cells) spiperone injection and respiration rate was monitored throughout the recording session (Fig. 6). Spiperone had no significant effect on respiration rate [paired $t(4)$ $=2.09$, NS].

Systemic spiperone mimicked the effects of olfactory deprivation on mitral/tufted cell responses to odors. As with deprivation, the proportion of cells responding to at least one odor was enhanced by spiperone, though not significantly [preinjection, mean $=36.2 \% \pm 4.0 ; 30-90 \mathrm{~min}$ postinjection, mean $=$ $50.4 \% \pm 5.8$; paired $t$ test, $t(4)=1.63, p=0.17]$. The proportion of cells responding to both odors was significantly increased
30-90 min post spiperone injection compared to cells recorded preinjection [paired $t(4)=3.48, p<0.05$ ]. Figure 7 compares the effects of spiperone in undeprived bulbs with the effects of deprivation on two-odor discrimination. Both olfactory deprivation and spiperone produced similar decreases in discrimination.

Furthermore, spiperone increased responsiveness to the higher concentrations of citral, as was shown with deprivation (Fig. 8). $A$ repeated measures ANOVA (pre/post-drug $\times$ citral intensity) revealed a significant effect of intensity $[F(2,12)=19.53, p<$ $0.01]$ and a significant effect of drug state $[F(1,12)=5.33, p$ $<0.05]$. Post hoc Fisher tests revealed a significant difference between groups in response rates to the $10^{-1}$ intensily $(p<$ 0.05 ).

Finally, an analysis of the relationship between firing rate and respiration phase revealed that spiperone had no obvious effect on this aspect of mitral/tufted cell activity. Activity in control cells often displayed a strong phase relationship with the respiration cycle (Fig. 9). As reported elsewhere (Macrides and Chorover, 1972), in somc cclls, activity peaked near the onset of inhalation and in others activity peaked during exhalation. A few cells showed no significant phase relationship with respiration. The probability of a significant single-unit activity-respiration cycle phase relationship was not affected by spiperone (cells showing significant phase relationship: prespiperone, 31/34 cells; post-spiperone, 33/35 cells).

\section{Discussion}

The present results demonstrate that late-onset olfactory deprivation, which has minimal neuroanatomical consequences in the rat (Brunjes and Borror, 1983), modifics mitral/tuftcd ccll rcsponse patterns to odors. Furthermore, the effects of olfactory deprivation on mitral/tufted cell responses can be mimicked by the $\mathrm{D}_{2}$ antagonist spiperone. While the present study utilized systemic injections of spiperone, given the striking similarity between the deprivation-induced, localized glomerular layer reduction in dopamine and the effects of systemic spiperone, it is assumed that the majority of spiperone's effects on mitral/tufted cell response patterns is due to action within the olfactory bulb.

We interpret these results as suggesting that one way in which olfactory stimulation modulates olfactory system function is through controlling dopaminergic inhibition. A decrease in olfactory stimulation reduces dopamine levels and releases afferent input from both feedback and lateral inhibition. Although there is a deprivation associated upregulation of $\mathrm{D}_{2}$ receptors in the bulb (Guthrie et al., 1991), this upregulation is apparently insufficient to completely compensate for the loss of dopamine. The result is an increase in the number of cells responding to odors at a given intensity and a decrease in odor discrimination (i.e., single cells respond to more odors). In turn, we suspect the converse to be also true; that is, increases in odor stimulation may enhance dopamine levels (Coopersmith et al., 1991), thus decreasing the number of cells responding to that odor (habituation?) and increasing odor discrimination. In fact, the dopamine agonist apomorphine reduces or eliminates focal glomerular layer 2-deoxyglucose uptake to odor stimulation (Sallaz and Jourdan, 1992). We are currently examining whether the effects of late-onset deprivation on mitral/tufted cell response patterns can be reduced or eliminated by dopamine agonists.

Dopamine does not appear to be significantly involved in entraining or shaping mitral/tufted cell activity to the respiratory cycle. The patterning of mitral/tufted cell firing is frequently 


\section{Late-onset, short term deprivation}

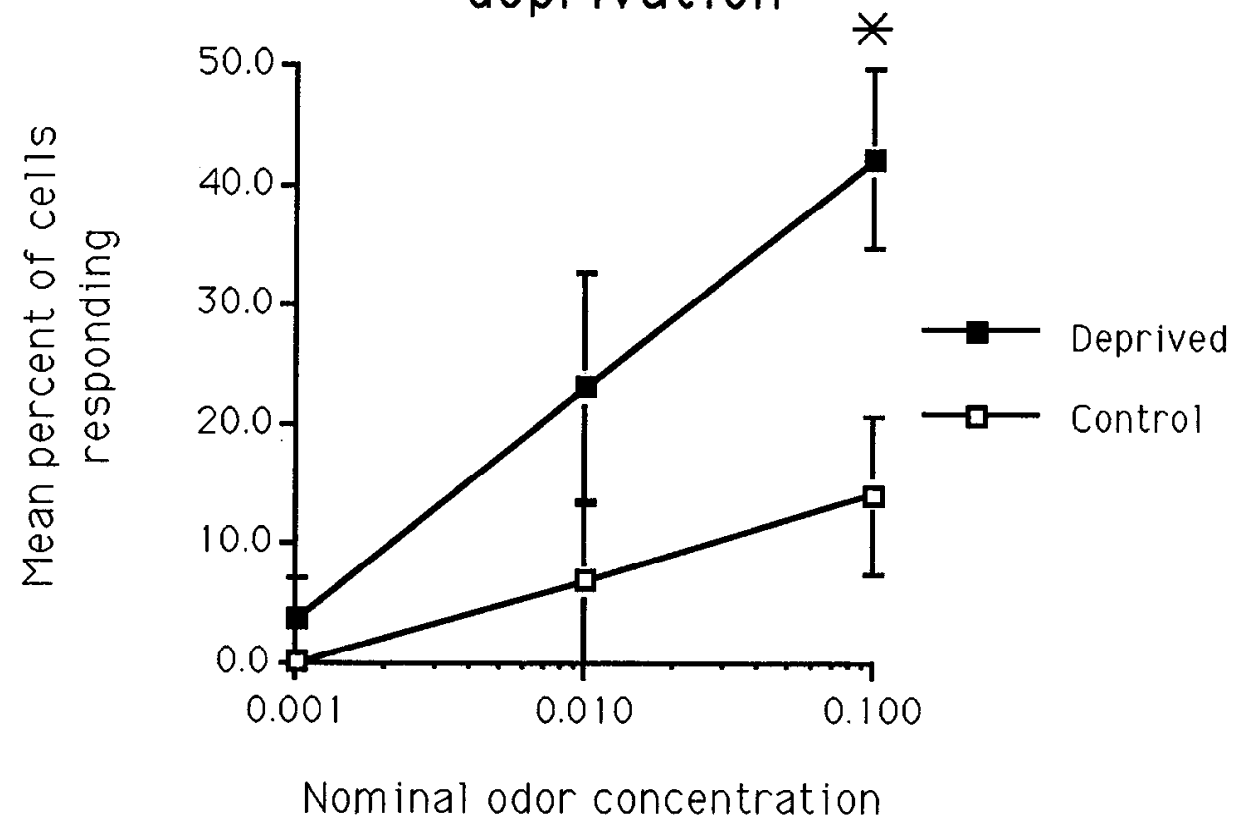

Figure 5. Effects of late-onset, shortterm deprivation on mitral/tufted cell responses to citral at different intensities. Deprivation had no effect on responses to the lowest intensity but significantly enhanced the probability of response to the higher intensities. Asterisk represents significant difference from control, $p<0.05$.

synchronized with respiration (Macrides and Chorover, 1972; Chaput et al., 1992). While centrifugal fibers modulate this phase relationship (Potter and Chorover, 1976; Ravel et al., 1987), olfactory nerve input and intrinsic olfactory bulb circuitry (feedback inhibition) appear to be the major influencing factors (Sobel and Tank, 1993). Juxtaglomerular interneurons, in particular, have been suggested to be important in this patterning (Sobel and Tank, 1993). However, the present results suggest that juxtaglomerular dopamine is probably not critically involved, at least at the level of analysis used here.

The underlying mechanism of dopamine modulation of mitral/ tufted cell response patterns to odors is not clear from the present study, although two (non-mutually exclusive) possibilities are presented in Figure 10. Mitral/tufted cells have been shown to respond to multiple odors, with a small subset of stimuli producing maximal responses (e.g., Imamura et al., 1992; Katoh et al., 1993). That group of stimuli to which the cell is responsive has been termed the molecular receptive range of the cell (Imamura et al., 1992). The molecular receptive range (or receptive field) is diagrammatically shown in Figure 10 as that range of odors along a hypothetical continuum of odor quality that can activate a given mitral/tufted cell with reasonably low thresholds.

One possible mechanism through which dopamine could influence mitral/tufted cell response patterns to produce the results obtained here is by decreasing response thresholds to all odors (or increasing response gain to all odors; Fig. 10A). Dopamine regulates the strength of primary olfactory nerve input into single glomeruli, apparently through a presynaptic inhibition of olfactory nerve glutamate release (Nickel et al., 1990; Berkowicz et al., 1994). Reductions in dopamine should, therefore, enhance the strength of presynaptic nerve input, thus making odors previously ineffective at activating a particular cell, now effective (e.g., odor "P" in Fig. 10), and allowing more cells to respond to a given odor. Evidence supporting this suggestion includes (1) early onset deprivation, which reduces glomerular layer dopamine, enhances maximal field potential amplitude evoked by olfactory nerve stimulation (Wilson and Wood, 1992); (2) early onset deprivation enhances both the intensity and lateral extent of glomerular layer 2-deoxyglucose uptake foci to odors (Guthrie et al., 1990); (3) both early (Guthrie et al., 1990) and late onset (present report) deprivation reduce dopamine and enhance

Cell: DOPA-3/17

Figure 6. Representative example of respiration data obtained with the piezoelectric monitoring of chest wall movements. Respiration waveforms were analyzed to produce a trigger pulse that was used to count respiration rate. Odor presented during horizontal bar.

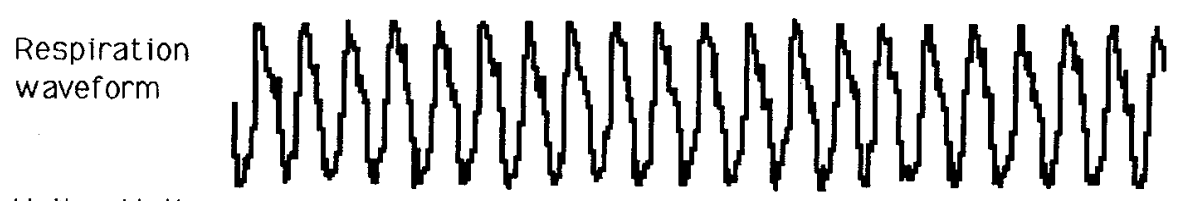

Unit activity

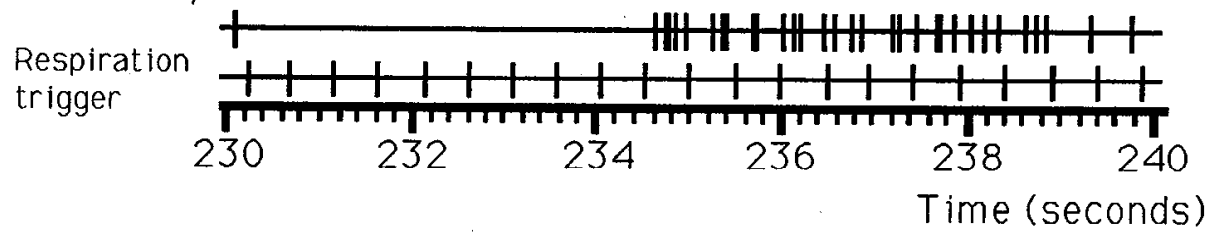




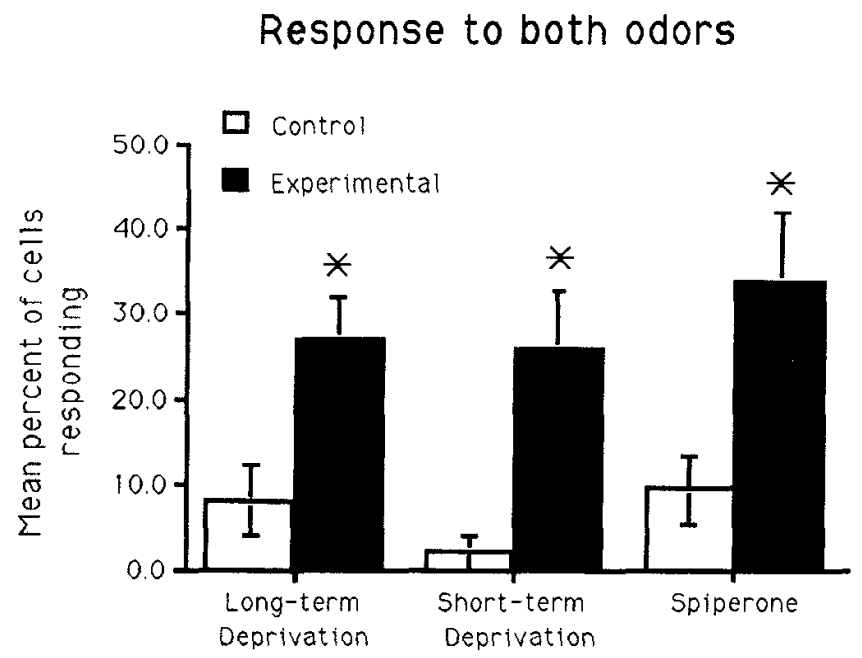

Figure 7. Effects of deprivation and spiperone on odor discrimination by mitral/tufted cell single units. The probability of a single mitral/ tufted cell responding to both test odors was significantly enhanced in all three conditions (Experimental) compared to controls (asterisks represent $p<0.05$ ).

mitral/tufted cell responses to single odors; (4) spiperone enhances mitral/tufted cell responses to odors (present report); and (5) in contrast to the physiological effects found here with a dopamine antagonist, the dopamine agonist quinpirole increases behavioral odor detection thresholds (Doty and Risser, 1989).

A second possible mechanism through which dopamine could modulate mitral/tufted cell response patterns is through changes in lateral inhibition and a direct increase in the size of an individual cell's receptive field (Fig. 10B). In the rat, mitral/tufted cells extend their apical dendrite into a single glomerulus. The current view of the glomerulus is as a functional unit (Shepherd, 1972), responding to a small group of odors en mass (Benson et al., 1985; Buonviso and Chaput, 1990). Thus, the deprivation/ spiperone induced decrease in odor discrimination could result
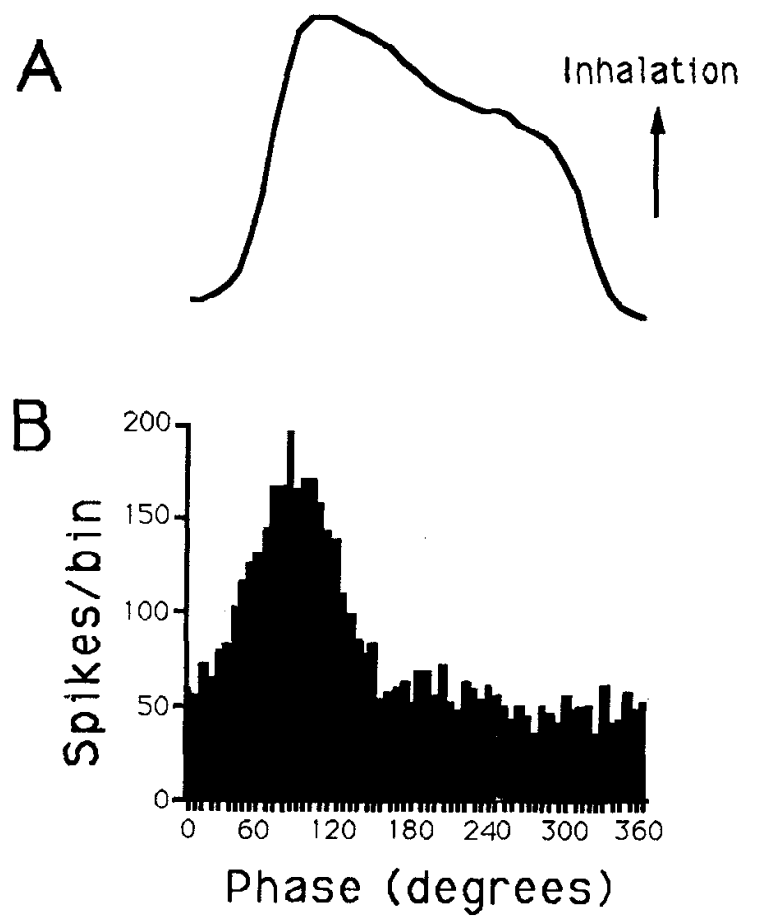

Figure 9. Representative example of single-unit activity-respiration phase relationship data. The averaged respiration waveform $(A)$ and the phase histogram $(B)$ are aligned to show the temporal relationship.

either from an unmasking of normally ineffective/subthreshold olfactory nerve inputs to that glomerulus (intra-glomerular inhibition), or from an increase in the effectiveness of inputs to the mitral/tufted cell's lateral dendrites through a decrease in inter-glomerular inhibition. Lateral connections, in the absence of activation of a mitral/tufted cell's apical dendrite, may be sufficient to drive responses by that cell to odors. Either of these scenarios could result from a decrease in glomerular layer inhibition, although the change in lateral, inter-glomerular inhibi-

\section{Spiperone}

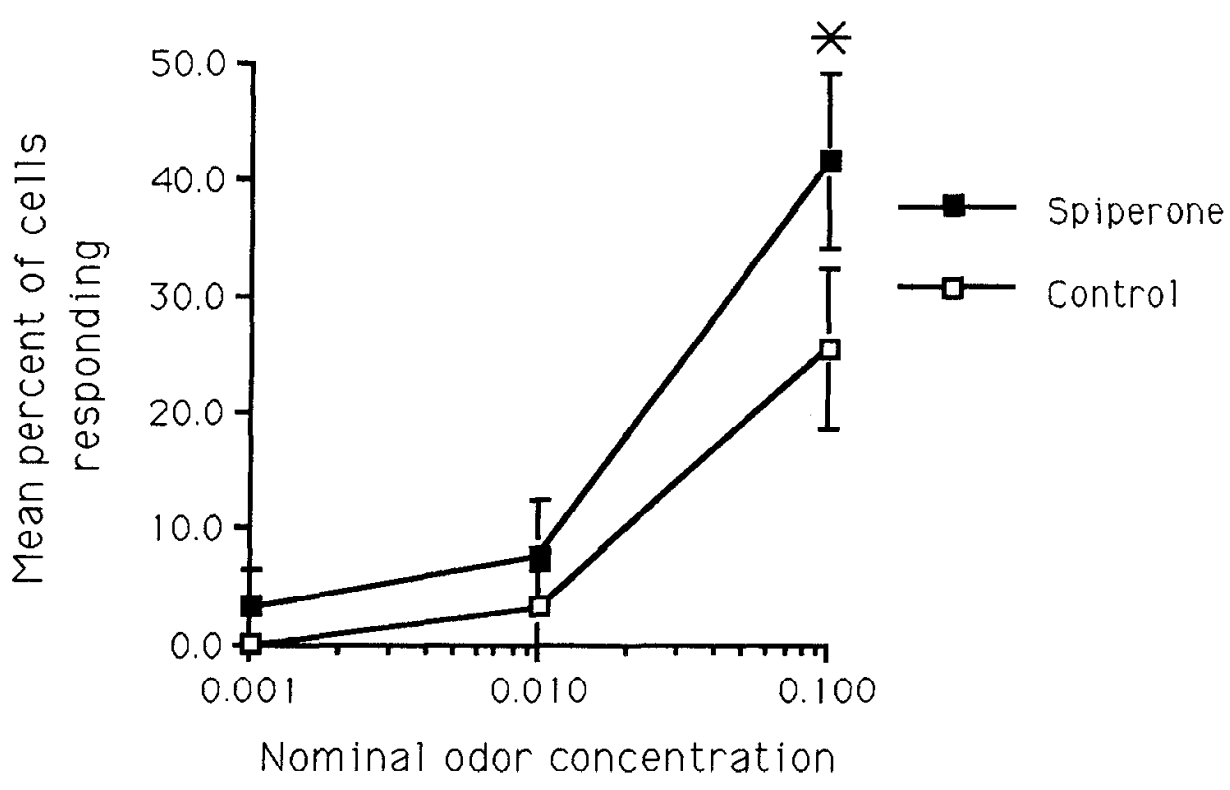

Figure 8. Effects of spiperone $(0.2$ $\mathrm{mg} / \mathrm{kg}$ ) on mitral/tufted cell responses to citral at different intensities. As with deprivation, spiperone had no effect on responses to the lowest intensity but significantly enhanced the probability of response to the higher intensities. Asterisk represents significant difference from control, $p<0.05$. 
Figure 10. Graphs of hypothetical mitral/tufted cell molecular receptive fields in normal and olfactory deprived or spiperone treated animals. $A, A$ decrease in threshold to all odors (or increase in gain) could increase the receptive range of single cells, producing the observed decrease in odor discrimination between citral $(C)$ and peppermint $(P)$, and also produce the observed increase in number of cells responding to single odors. Thus, in the example shown here, initially, the cell only responds to peppermint at intensities $>10^{-1}$. After deprivation or spiperone, the cell will respond to lower intensities of peppermint. $B, A$ decrease in lateral inhibition and/or increase in receptive field size, in the absence of any change in threshold, could also produce a decrease in odor discrimination and increase in number of cells responding to single odors.
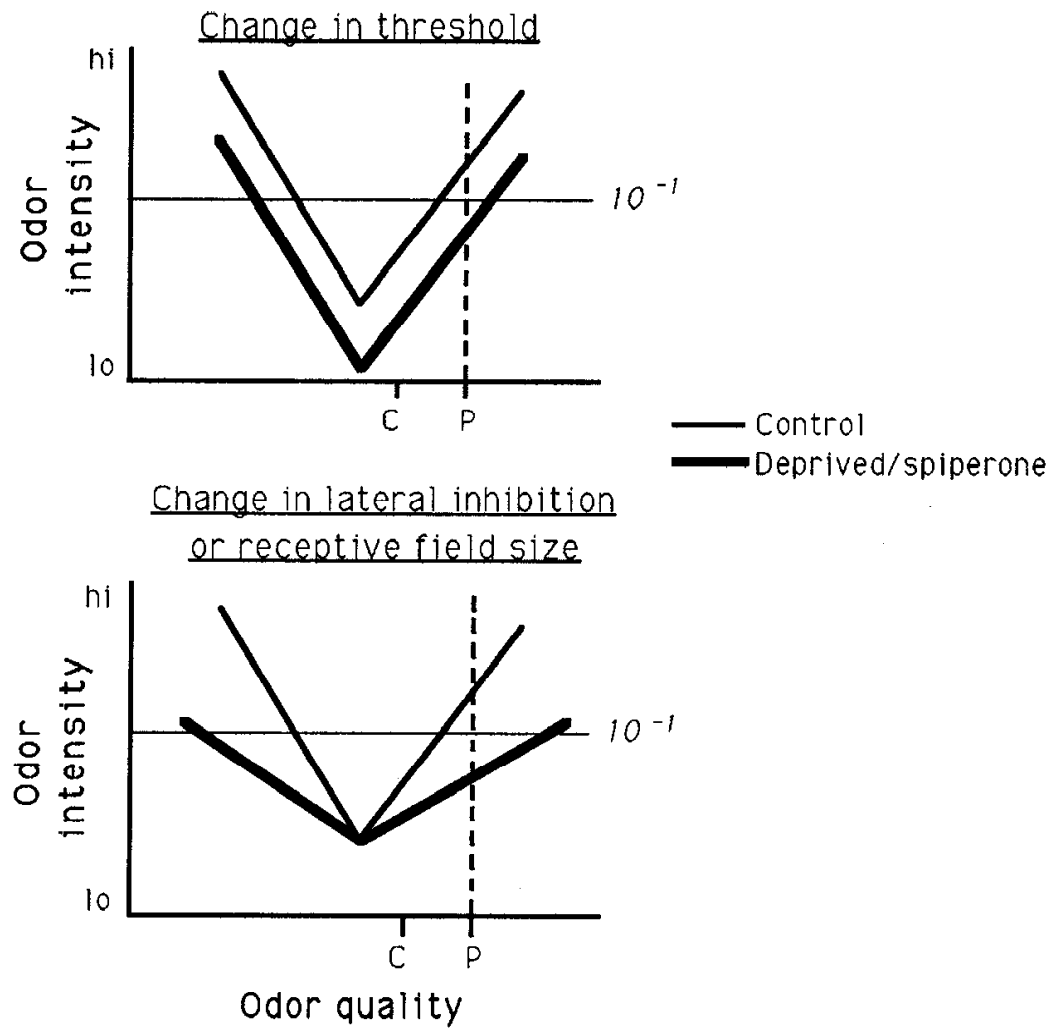

tion seems more plausible. The result would, again, be single cells responding to more odors, and more cells responding to individual odors. Interestingly, early onset deprivation has been shown to increase the size (lateral extent) of focal glomerular layer 2-DG uptake to odors (Guthrie et al., 1990). Further testing with a larger set of odors should help clarify these issues.

It should be noted that it is not clear from these results if dopamine is always directly inhibitory (Berkowicz et al., 1994) or if dopamine also serves a modulatory role in inhibition, by influencing GABAergic interneurons in the bulb. As stated above, there are both dopaminergic and GABAergic neurons in the glomerular layer, as well as the more numerous GABAergic granule cells in the granule cell layer. Dopamine could be influencing bulb function by modulating these or other neurons. For example, in the frog, glomerular layer GABAergic neurons appear to modulate mitral/tufted cell response threshold to odors (Duchamp-Viret et al., 1993), while granule cell layer GABAergic neurons appear to modulate mitral/tufted cell response duration and/or response intensity to odors (Duchamp-Viret and Duchamp, 1993).

Finally, the similarity of the effects of deprivation on bulb function to the effects reported for dark-adaptation on the mammalian retina are striking, and leads to speculations about other similarities. For example, the strength of inhibitory surrounds of retinal ganglion cell center-surround receptive fields is reduced by dark adaptation (Barlow et al., 1957), through a dark-induced decrease in dopamine (Luvone et al., 1978), that reduces lateral inhibition (Jensen and Daw, 1986; Thier and Alder, 1984). Our results suggest that in the olfactory bulb, mitral/tufted cell receptive fields are similarly modified by odor deprivation, through a decrease in dopamine modulated lateral/feedback inhibition. In the retina, dark-adaptation effects are evident within minutes (Daw et al., 1989). We predict that, similarly, odor deprivation may modify mitral/tufted cell response patterns much more rapidly than has been tested thus far $(>20 \mathrm{~d})$. In fact, protein synthesis is reduced in the olfactory bulb within hours after carly deprivation onset (Korol and Brunjes, 1990).

In fish and turtle retina, one way that dopamine exerts control over lateral inhibition is through modulation of gap junctions between inhibitory interneurons (Daw et al., 1989; DeVries, Baylor, 1993). This effect occurs at a distance from the dopamine release site (Daw et al., 1989). In the olfactory bulb, the major class of inhibitory interneuron, granule cells, are also linked through gap junctions (Reyher et al., 1991). Thus, granule cell gap junctions may also be modulated by dopamine release in the glomerular or external plexiform layer. Decreasing gap junctions and electrotonic coupling could further reduce lateral inhibition. However, granule cell mediated inhibition evoked by LOT stimulation is not affected by the dopamine depletion associated with late onset deprivation (Fig. 2 and Wilson and Wood, 1992).

In summary, during periods of limited sensory input, olfactory bulb performance is modified to facilitate response to a stimulus. This facilitation comes at the expense of a decrease in odor discrimination. These events mimic those that occur in the retina during dark adaptation and may be due to comparable mechanisms. Experiments are currently underway to explore the behavioral consequences of these deprivation-induced changes in olfactory system physiology.

\section{References}

Baker H (1990) Unilateral, neonatal olfactory deprivation alters tyrosine hydroxylase expression but not aromatic amino acid decarboxylase or GABA immunoreactivity. Neuroscience 36:761-771.

Barlow HB, Fitzhugh R, Kuffler SW (1957) Change of organization in the receptive fields of the cat's retina during dark adaptation. $J$ Physiol (Lond) 137:338-354.

Benson TE, Burd GD, Greer CA, Landis DMD, Shepherd GM (1985) 
High resolution 2-deoxyglucose autoradiography in quick-frozen slabs of neonatal rat olfactory bulb. Brain Res 339:67-78.

Berkowicz DÁ, Trombley PQ, Shepherd GM (1994) Dopaminergic modulation at the olfactory nerve synapse. Soc Neurosci Abstr 20: 328.

Brunjes PC (1994) Unilateral naris closure and olfactory system development. Brain Res Rev 19:146-160.

Brunjes PC, Borror MJ (1983) Unilateral odor deprivation: differential effects due to time of treatment. Brain Res Bull 11:501-503.

Brunjcs PC, Smith-Crafts LK, McCarty R (1985) Unilateral odor deprivation: effects on the development of olfactory bulb catecholamines and behavior. Dev Brain Res 22:1-6.

Buonviso N, Chaput MA (1990) Response similarity to odors in olfactory bulb output cells presumed to be connected to the same glomerulus: electrophysiological study using simultaneous single-unit recordings. J Neurophysiol 63:447-454.

Chaput MÁ, Buonviso N, Berthommer F (1992) Temporal patterns in spontaneous and odour-evoked mitral cell discharges recorded in anesthetized freely breathing animals. Eur J Neurosci 4:813-822.

Coopersmith R, Weihmuller FB, Kirstein CL, Marshall JR, Leon M (1991) Extracellular dopamine increases in the neonatal olfactory bulb during odor preference training. Brain Res 564:149-153.

Cummings DM, Brunjes PC (1994) Changes in cell proliferation in the developing olfactory epithelium following neonatal unilateral naris occlusion. Exp Neurol 128:124-128.

Daw NW, Brunken WJ, Parkinson D (1989) The function of synaptic transmitters in the retina. Annu Rev Ncurosci 12:205-225.

DeVries SH, Baylor DA (1993) Synaptic circuitry of the retina and olfactory bulb. Neuron 10:139-149.

Doty RL, Risser JM (1989) Influence of the D-2 dopamine receptor agonist quinpirole on the odor detection performance of rats before and after spiperone injection. Psychopharmacology 98:310 315 .

Duchamp-Viret P, Duchamp A (1993) GABAergic control of odourinduced activity in the frog olfactory bulb: possible GABAergic modulation of granule cell inhibitory action. Neuroscience 56:905-914.

Duchamp-Viret P, Duchamp A, Chaput M (1993) GABAergic control of odour-induced activity in the frog olfactory bulb. Electrophysiological study with picrotoxin and bicuculline. Neuroscience 53:111120.

Farbman AI, Brunjes PC, Rentfro L, Michas J, Ritz S (1988) The effects of unilateral naris occlusion on cell dynamics in the developing rat olfactory epithelium. J Neurosci 8:3290-3295.

Frazier LL, Brunjes PC (1988) Unilateral odor deprivation: early postnatal changes in olfactory bulb density and number. J Comp Neurol 269:355-370.

Gall CM, Hendry SHC, Seroogy KB, Jones EG, Haycock JW (1987) Evidence for coexistence of GABA and dopamine in neurons of the rat olfactory bulb. J Comp Neurol 266:307-318.

Guthrie KM, Wilson DA, Leon M (1990) Early unilateral deprivation modifies olfactory bulb function. J Neurosci 10:3402-3412.

Guthrie KM, Pullara JM, Marshall JF, Leon M (1991) Olfactory deprivation increases D2 receptor density in the rat olfactory bulb. Synapse 8:61-70

Imamura, K, Mataga, N, Mori, K (1992) Coding of odor molecules by mitral/tufted cells in rabbit olfactory bulb. I. Aliphatic compounds. J Neurophysiol 68:1986-2002.

Luvone PM, Galli CL, Garrison-Gund CK, Neff NH (1978) Light stimulates tyrosine hydroxylase activity and dopamine synthesis in retinal amacrine neurons. Science 202:901-902.

Jensen RJ, Daw NW (1986) Effects of dopamine and its agonists and antagonists on the receptive field properties of ganglion cells in the rabbit retina. Neuroscience 17:837-855.

Jourdan F, Duveau A, Astic L, Holley A (1980) Spatial distribution of ${ }^{14} \mathrm{C}$-2-deoxyglucose uptake in the olfactory bulbs of rats stimulated with two different odours. Brain Res 188:139-154.

Katoh K, Koshimoto H, Tani A, Mori K (1993) Coding of odor molecules by mitral/tufted cells in rabbit olfactory bulb. II. Aromatic compounds. J Neurophysiol 70:2161-2175.

Korol DL, Brunjes PC (1990) Rapid changes in 2-deoxyglucose uptake and amino acid incorporation following unilateral odor deprivation: a laminar analysis. Dev Brain Res 52:75-84.

Macrides F, Chorover SL (1972) Olfactory bulb units: activity correlated with inhalation cycles and odor quality. Science 175:84-87.

Mangel SC, Dowling JE (1985) Responsiveness and receptive field size of carp horizontal cells are reduced by prolonged darkness and dopamine. Science 209:1107-1109.

Maruniak JA, Taylor JA, Hengar JR (1989) Unilateral naris closure in adult mice: atrophy of the deprived-side olfactory bulbs. Dev Brain Res 47:27-33.

Meisami E (1976) Effects of olfactory deprivation on postnatal growth of the rat olfactory bulb utilizing a new method for production of neonatal unilateral anosmia. Brain Res 107:437-444.

Meisami E, Safari L (1981) A quantitative study of the effects of early unilateral olfactory deprivation on the number and distribution of mitral and tufted cells and of glomeruli in the rat olfactory bulb. Brain Res 221:81-107.

Mori K (1987) Membrane and synaptic properties of identified neurons in the olfactory bulb. Prog Neurobiol 29:275-320.

Movshon IA, Kiorpes L (1990) The role of experience in visual development. In: Development of sensory systems in mammals (Coleman JR, ed), pp 155-202. New York: Wiley.

Nickell WT, Norman AB, Wyatt LM, Shipley MT (1990) Localization of dopamine receptor subtypes in the olfactory bulb: $\left[{ }^{3} \mathrm{H}\right]$ spiperone (D2) binding in the glomerular and nerve layers. Soc Neurosci Abstr 16:101.

Potter H, Chorover SL (1976) Response plasticity in hamster olfactory bulb: peripheral and central processes. Brain Res 116:417-429.

Ravel N, Caille D, Pager J (1987) A centrifugal respiratory modulation of olfactory bulb unit activity: a study on acute rat preparation. Exp Brain Res 65:623-628.

Reyher CKH, Lubke J, Larsen WJ, Hendrix GM, Shipley MT, Baumgarten HG (1991) Olfactory bulb granule cell aggregates: morphological evidence for interperikaryal electrotonic coupling via gap junctions. J Neurosci 11:1485-1495.

Sallaz M, Jourdan F (1992) Apomorphine disrupts odour-induced patlerns of glomerular activation in the olfactory bulb. Neuroreport 3:833-836.

Shepherd GM (1972) Synaptic organization of the mammalian olfactory bulb. Physiol Rev 52:864-917.

Sobel EC, Tank DW (1993) Timing of odor stimulation does not alter patterning of olfactory bulb unit activity in freely breathing rats. $\mathrm{J}$ Neurophysiol 69:1331-1337.

Thier P, Alder V (1984) Action of iontophoretically applied dopamine on cat retinal ganglion cells. Brain Res 292:109-121.

Wilson DA, Wood JG (1992) Functional consequences of unilateral olfactory deprivation: time-course and age sensitivity. Neuroscience 49:183-192.

Wilson DA, Guthrie KM, Leon M (1990) Modification of olfactory bulb synaptic inhibition by early unilateral olfactory deprivation. Neurosci Lett 116:250-256. 